\title{
Trends in and predictors of pregnancy termination among 15-24 year-old women in Nigeria: a multi-level analysis of demographic and health surveys 2003- 2018
}

Franklin I. Onukwugha ${ }^{1}$, Monica A. Magadi ${ }^{2}$, Ahmed M. Sarki ${ }^{3}$ and Lesley Smith ${ }^{1 *}$ (D)

\begin{abstract}
Background: Three-quarters of pregnancy terminations in Africa are carried out in unsafe conditions. Unsafe abortion is the leading cause of maternal mortality among 15-24 year-old women in Sub-Saharan Africa. Greater understanding of the wider determinants of pregnancy termination in 15-24 year-olds could inform the design and development of interventions to mitigate the harm. Previous research has described the trends in and factors associated with termination of pregnancy for women of reproductive age in Nigeria. However, the wider determinants of pregnancy termination have not been ascertained, and data for all women have been aggregated which may obscure differences by age groups. Therefore, we examined the trends in and individual and contextual-level predictors of pregnancy termination among 15-24 year-old women in Nigeria.

Methods: We analysed data from the 2003, 2008, 2013 and 2018 Nigerian Demographic and Health Surveys (NDHS) comprising 45,793 women aged 15-24 years. Trends in pregnancy termination across the four survey datasets were examined using bivariate analysis. Individual and contextual predictors of pregnancy termination were analysed using a three-level binary logistic regression analysis and are reported as adjusted odds ratios (aOR) with 95\% confidence intervals (Cl).

* Correspondence: Lesley.smith@hull.ac.uk

'Institute for Clinical and Applied Health Research, Faculty of Health Sciences University of Hull, Hull, UK

Full list of author information is available at the end of the article

(c) The Author(s). 2020 Open Access This article is licensed under a Creative Commons Attribution 4.0 International License, which permits use, sharing, adaptation, distribution and reproduction in any medium or format, as long as you give appropriate credit to the original author(s) and the source, provide a link to the Creative Commons licence, and indicate if changes were made. The images or other third party material in this article are included in the article's Creative Commons licence, unless indicated otherwise in a credit line to the material. If material is not included in the article's Creative Commons licence and your intended use is not permitted by statutory regulation or exceeds the permitted use, you will need to obtain permission directly from the copyright holder. To view a copy of this licence, visit http://creativecommons.org/licenses/by/4.0/. The Creative Commons Public Domain Dedication waiver (http://creativecommons.org/publicdomain/zero/1.0/) applies to the data made available in this article, unless otherwise stated in a credit line to the data. 


\begin{abstract}
(Continued from previous page)
Results: Trends in pregnancy termination declined from 5.8\% in 2003 to 4.2\% in 2013 then reversed to 4.9\% in 2018. The declining trend was greater for 15-24 year-old women with higher socioeconomic status. Around 17\% of the total variation in pregnancy termination was attributable to community factors, and $7 \%$ to state-level factors. Of all contextual variables considered, only contraceptive prevalence (proxy for reproductive health service access by young women) at community level was significant. Living in communities with higher contraceptive prevalence increased odds of termination compared with communities with lower contraceptive prevalence (aOR=4.2;95\% $\mathrm{Cl}$ 2.7-6.6). At the individual-level, sexual activity before age 15 increased odds of termination ( $\mathrm{aOR}=2.3 ; 95 \% \mathrm{Cl} 1.9-2.8$ ) compared with women who initiated sexual activity at age 18 years or older, and married women had increased odds compared with never married women ( $\mathrm{aOR}=3.0 ; 95 \% \mathrm{Cl} 2.5-3.7$ ).

Conclusion: Our findings highlight the importance of disaggregating data for women across the reproductive lifecourse, and indicates where tailored interventions could be targeted to address factors associated with pregnancy termination among young women in Nigeria.
\end{abstract}

Keywords: Maternal health, Adolescence, Health inequalities, Sustainable development goals, Prevalence, Low middle income countries

\section{Background}

Pregnancy termination or induced abortion, defined as a pregnancy that is terminated by choice through intervention, is a major public health issue in Africa [1]. Abortion services in Africa are restricted with only 4 out of 54 countries having relatively liberal abortion laws [1]. Between 2010 and 2014, of the 6.86 million abortions carried out each year in Africa, 75.6\% (95\% confidence interval (CI) 66.4 to $81.4 \%$ ) of these were classified as unsafe (using untrained practitioners and/or nonrecommended methods) [2]. Unsafe abortion has serious adverse health consequences such as infections and fatality [2]. Young women aged 15-24 years account for $57 \%$ of abortions in Sub-Saharan Africa (SSA) [3], with unsafe abortion being the leading cause of maternal mortality in this age group [4-7].

In Nigeria, the situation is further exacerbated by socio-cultural and religious beliefs whereby termination of pregnancy is viewed as murder and carries harsh penalties for providers $[8,9]$. These factors contribute to women seeking clandestine abortion services with private providers who are mostly untrained, carry out procedures in unsafe environments using dangerous invasive methods $[10,11]$. Notwithstanding, the punitive abortion laws in Nigeria, in 2012 the incidence of induced abortion was estimated as 33 per 1000 women [12]. More recently a pooled analysis of the Nigerian Demographic and Health Survey data (NDHS) for 20032013 reported the percent of married women who had ever terminated a pregnancy as $3.8 \%$ (95\% CI 3.3 to 4.2\%) amongst $15-19$-year olds, and $11.7 \%$ (95\% CI 11.0 to $12.5 \%$ ) for $20-24$-year olds [13].

While much research has been published reporting on young people's knowledge, attitudes, practices and prevalence of pregnancy termination in SSA especially in Nigeria [3, 9, 12, 14], fewer studies have investigated factors influencing termination. The prevalence of pregnancy termination is higher in women of older age $[8,15$, 16]; young age of sexual debut [17]; employed women [13], unintended pregnancy $[8,16]$, forced or transactional sex [18], physical or sexual intimate partner violence [19, 20], higher number of living children $[18,21]$, and higher wealth index [13, 22]. Being married $[8,13,22,23]$, having a secondary education $[15,22,24]$, modern contraceptive use [23] and residing in rural areas have been associated with lower prevalence of induced abortion $[13,15]$.

Socio-cultural factors such as religion, mass media, and ethnicity have also been found to influence termination of pregnancy among adolescents and young people [8]. At the community and societal levels, place of residence, region of residence, community (mean education, attitudes justifying wife-beating, median age of first marriage, contraceptive use) and facility-level factors (policy, limited availability of health facilities providing abortion services and lack of patient-centredness of health services) have been noted to significantly predict termination of pregnancy $[20,23,25]$.

Although the evidence above sheds light on some factors that are associated with pregnancy termination in women overall, they fall short of ascertaining the determinants specifically for 15-24 year-old women in Nigeria. The studies that involved young people were of adolescents in school [16, 17] and sample sizes were small and not representative of the general population, limiting inferences that can be drawn from the findings. Moreover, the studies largely focused on individual-level socio-economic and demographic factors with limited attention on the contextual community and state-level factors that influence pregnancy termination. Ignoring these factors especially in Nigeria with wide variation in socio-economic/cultural and regional characteristics hampers development of interventions to mitigate early 
pregnancy among 15-24 year-old women [26]. Furthermore, empirical studies outside of SSA have shown that contextual level factors such as cultural norms, inadequate quality or lack of sexual health education in schools, and lack of youth-friendly services may influence pregnancy termination among young people $[27,28]$.

One of the targets of the UN Sustainable Development Goals (SDG) is to reduce the global maternal mortality ratio to fewer than 70 per 100,000 live births by 2030 . Reaching this target in Nigeria would require a maternal mortality ratio reduction of $7.5 \%$ per year [29]. The mortality burden among 15-24 year-old women due to unsafe abortion, along with the limitations in the previous studies, underscores the importance of understanding what factors influence pregnancy termination amongst this age group in Nigeria. Such knowledge would be of value to inform the development of tailored interventions and programmes to reduce the burden of maternal morbidity and mortality [30] particularly in Northern Nigeria- the region with the highest maternal and under-five mortality in the country [31]. Our aim was to examine the trends in prevalence of pregnancy termination, and the individual and contextual-level factors that influence pregnancy termination among 15-24 year-old women in Nigeria.

\section{Methods}

\section{Study design}

Cross-sectional study design.

\section{Data source and sample of participants}

Data for this study were based on four datasets from the 2003, 2008, 2013 and 2018 Nigerian Demographic Health Survey (NDHS). The NDHS is a nationallyrepresentative household survey implemented by the Nigeria National Population Commission and Measure DHS with financial and technical support from global development agencies such as USAID [32]. The NDHS data were collected using a 2-phase multistage, stratified and clustered sampled design based on a list of enumerated area (EAs). At the first stage, a random sample of clusters were drawn from the 36 states and Federal Capital Territory (FCT) using the census files. In the second stage, a random sample of households was selected from each cluster using a household list from a national master sampling frame. Details of the NDHS sampling procedures and questionnaire are available elsewhere [32]. The data used in the analyses were weighted in order to adjust for differences in the probability of selection and to adjust for non-response. A total of 121,774 women aged 15-49 were interviewed in the four surveys. The NDHS includes all women age 15-49 in the sample households, and therefore can include minors aged 1516 years. The sample used in this analysis was limited to women aged 15-24 years giving a total sample size of 45,793 . Sample characteristics are given in annex (i).

\section{Outcome variable}

The outcome variable for this study was 'ever termination of pregnancy' reported by the respondent. Pregnancy termination is defined in the NDHS as any pregnancy that resulted in a miscarriage, abortion or stillbirth [32]. This definition is commonly used in studies in SSA in order to mitigate social desirability bias $[13,20,33]$. Young women may recast their experience of induced abortion to a miscarriage or stillbirth as it is less stigmatised and not prohibited by law.

\section{Explanatory variables}

The explanatory variables (both individual and contextual) were selected on the basis of an association with the outcome reported in studies identified in a scoping review of the literature to inform the analysis, and on the availability of variables in the NDHS datasets (Table 1). The community-level factors (community-wealth index, community-level education, community-level mass media (radio, TV and newspaper) exposure and community-level contraceptive prevalence) and state-level factors (statelevel wealth index, state-level education and state-level mass media exposure) among 15-24 year-old women were derived from individual-level measures. For example, contraceptive prevalence among 15-24 year-old women at community level was derived from the individual-level variable 'contraceptive use' and used as a proxy for reproductive health service access among 15-24 year-old women within a community/cluster.

\section{Data analysis}

Trends in pregnancy termination across the four datasets (2003-2018) and associations between each of the explanatory variables with pregnancy termination were examined using bivariate analysis. All bivariate associations were based on weighted percentages to enable examination of patterns across different regions of the country. Individual and contextual predictors of pregnancy termination were examined using a three-level binary logistic regression analysis on pooled data for all four datasets and are reported as adjusted odds ratios $(\mathrm{aOR})$ with $95 \%$ confidence intervals $(\mathrm{CI})$. We assessed potential collinearity between the explanatory variables, before adding variables to the multilevel models. None of the variables included in the multivariate model were highly correlated, and there was no evidence of multicollinearity.

The multilevel analysis placed particular emphasis on community and state variations in pregnancy termination among young people in Nigeria. The pooled NDHS data used in the multilevel analysis have a 
Table 1 Description of explanatory variables

\begin{tabular}{ll}
\hline Variables & Definitions \\
\hline Year of survey & Survey years classified into 4 groups 2003; 2008, 2013 and 2018. \\
Age group & Age group of respondents at the time of the survey classified into 2 groups: 15-19 and 20-24 years \\
Education & Education attainment of the women classified into 3 groups: no education, primary; secondary and above \\
Marital status & $\begin{array}{l}\text { Classified into } 4 \text { groups: never married; currently married; living with a partner (but not legally married) and } \\
\text { previously married (widowed, divorced, separated). }\end{array}$ \\
Wealth index & Constructed by the DHS using principal components analysis based on household assets. Classified into five \\
& groups: Poorest; Poorer; Middle; Richer and Richest. \\
Contraceptive use & $\begin{array}{l}\text { Denotes percentage of women in a cluster/state who currently use contraceptive methods. At individual level, } \\
\text { this is a dichotomous variable classified as users and nonusers }\end{array}$ \\
Age at first sex & Classified into 2: Never had sex; Less than age 15; 15-17 and 18+ years \\
Forced sex & Ever forced to perform unwanted sexual acts. Classified into 2 groups: Yes and No \\
Frequency of reading newspaper & Classified into 3 groups: Not at all; Less than once a week and at least once a week or more. \\
Frequency of listening to radio & Classified into 3 groups: Not at all; Less than once a week and at least once a week or more. \\
Frequency of watching TV & Classified into 3 groups: Not at all; Less than once a week and at least once a week or more. \\
No of living children & Number of living children at the time of the interview. Classified into 4 groups; 0, 1, 2 and $3^{+}$ \\
Ethnicity & Ethnic origin of respondents classified into 4 groups: Hausa; lgbo; Yoruba and Others \\
Religion & Religious affiliation of respondents, classified into 3 groups: Catholic; other Christians and Islam. \\
Place of Residence & Place of residence, grouped into 2: Urban and rural \\
Region & Region of residence grouped into 6: North Central, North East; North West; South East; South South; South West. \\
\hline
\end{tabular}

hierarchical structure with individuals nested within communities (clusters) which in turn were nested within states. In the multilevel analysis applied in this paper, states constituted the highest (third) level $(n=36)$, while communities (i.e clusters) within states constituted the second level. The general form of the three-level random intercepts [34] logistic regression model used may be expressed as:

$$
\text { Logit } \pi_{i j k}=X_{i j k}^{\prime} \beta+u_{j k}+v_{k}
$$

where: $\pi_{\mathrm{ijk}}$ is the probability of pregnancy termination (ever had terminated pregnancy) for an individual $i$, in the $j^{\text {th }}$ community in the $k^{\text {th }}$ state; $X_{i j k}^{\prime}$ is the vector of covariates which may be defined at the individual, community or state level; $\beta$ is the associated vector of usual regression parameter estimates; and the quantities $v_{k}$ and $u_{j k}$ are the residuals at the state and community level, respectively. These are assumed to have normal distribution with mean zero and variances $\sigma_{v}^{2}$ and $\sigma_{u}^{2}$ [34].

The estimates of state and community level variances are used to calculate intra-unit correlation coefficients (ICC) to examine the extent to which pregnancy termination among 15-24 year-olds are clustered within states (or communities within states) in Nigeria. We note that the intra-community correlation includes state correlations since individuals within the same community are also within the same state [35]. Therefore, the formulae for intra-community $\left(\rho_{u}\right)$ and intra-state $\left(\rho_{v}\right)$ correlation coefficients are given by:

$$
\begin{gathered}
\rho_{u}=\frac{\sigma_{u}^{2}+\sigma_{v}^{2}}{\sigma_{v}^{2}+\sigma_{u}^{2}+\sigma_{e}^{2}} \\
\rho_{v}=\frac{\sigma_{v}^{2}}{\sigma_{v}^{2}+\sigma_{u}^{2}+\sigma_{e}^{2}}
\end{gathered}
$$

where:

$\sigma_{\mathrm{v}}^{2}$ - is the state level variance;

$\sigma_{\mathrm{u}}{ }^{2}$ - is the community (cluster) level variance; and

$\sigma_{e}^{2}$ - is the individual level variance.

The level-1 residuals (for a logistic regression model), $\mathrm{e}_{\mathrm{ijk}}$, are assumed to have a standard logistic distribution with a mean of zero and variance of $\pi^{2} / 3$, where $\pi$ is the constant 3.1416 (See [35]). The multilevel analysis was carried out using MLwiN software and estimates of parameters based on second order Predictive QuasiLikelihood (PQL) procedure [36].

\section{Results}

Trends in pregnancy termination among 15-24 year-old women in Nigeria 2003-2018

Overall, there was significant differences in pregnancy termination between the survey years. Pregnancy termination among 15-24 year olds significantly declined $(P<0.001)$ from $5.8 \%$ in 2003 to $4.2 \%$ in 2013 then increased up to $4.9 \%$ in 2018 in Nigeria (Fig. 1). The overall declining trend was apparent for most explanatory variables examined in the bivariate analysis. The results in Table 2 show a differential pattern in pregnancy termination such that young women who had no education 


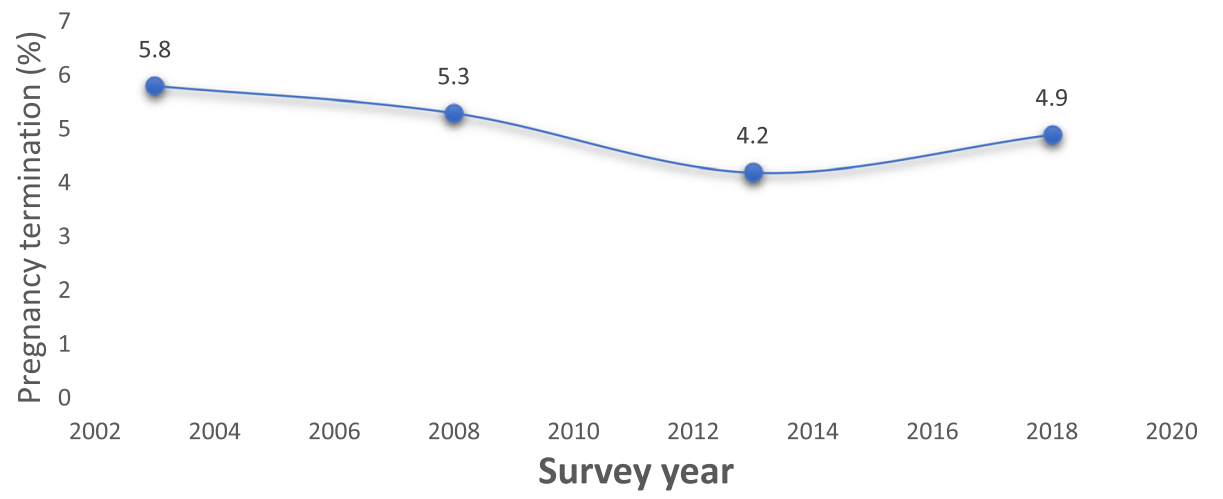

Fig. 1 Pregnancy termination among young women aged 15-24 years 2003-2018 in Nigeria

or primary education only, those from the poorer/poorest households, those who had sexual debut at age younger than 15 years, women from Hausa ethnic group, women of Islamic faith and those who live in rural areas showed no substantial decline in pregnancy termination and in some cases increased across the survey years, contrary to patterns observed among their counterparts. For example, pregnancy termination decreased from $5.7 \%$ in 2003 to $3.5 \%$ in 2018, among urban women, but increased from $5.8 \%$ in 2003 to $6.0 \%$ in 2018 among their rural counterparts. Similar pattern exists across the ethnic groups such that pregnancy termination increased from $6.6 \%$ in 2003 to $7.0 \%$ in 2018 among women of Hausa ethnic background, but decreased from $4.0 \%$ in 2003 to $1.7 \%$ in 2018 among women from the Igbo ethnic group (Table 2).

\section{Percentage distribution of pregnancy termination in women aged 15-24 years in Nigeria by socio- demographic and potential explanatory factors}

The percentages of women aged 15-24 years who reported ever termination of pregnancy for all years combined are shown in Table 2. For all years combined, it shows that a higher percentage of women with no education (6.5\%) and primary education (6.9\%) reported termination of pregnancy compared with young women with secondary education and above (3.5\%). Women of Hausa ethnic group (6.4\%) were more likely to report pregnancy termination than those from Igbo (2.5\%) and Yoruba (2.4\%) ethnic groups. A higher proportion of women of Islamic faith (5.5\%) reported pregnancy termination than the Catholic (3.6\%) and other Christians (4.3\%). More women who reported 'ever use of contraceptives' (9.9\%) reported pregnancy termination than women who reported 'never used contraceptives' (4.3\%). Regional differences in pregnancy termination across the survey years are apparent such that young women from the Northern region were more likely to report terminated pregnancy than those from the Southern region.

\section{Multilevel results of the predictors of pregnancy} termination in women aged 15-24 years in Nigeria Predictors of pregnancy termination based on a threelevel multilevel model, taking State as Level 3 and Cluster as Level-2 are presented in Table 3. Only significant factors, after controlling for the effect of other covariates, were included in the final model. Some individuallevel factors, such as religion, ceased to be significant once other factors were included in the model. Both wealth and region ceased to be significant, once a significant contextual factor - i.e. contraceptive prevalence among young women in a cluster - was included in the model. The interaction of individual variables with year of survey were tested to assess whether the effects of any of the predictors varied across time, but none were significant. Of all contextual factors considered, including wealth, education, contraceptive prevalence (proxy for $\mathrm{RH}$ service access by young women), media exposure at both cluster and state levels, only contraceptive prevalence at cluster level was significant.

The multilevel results shown in Table 3 confirm the findings from the crude analysis of trends over time and show a declining trend in pregnancy termination among women aged 15-24 years up to 2013, which reverses in 2018, after significant individual and contextual predictors were controlled for. There was a $34 \%$ reduction in the odds of pregnancy termination in 2013 compared with 2003, but no evidence of a significant difference in 2008 and 2018 compared with 2003.

Living in communities with higher contraceptive prevalence increased the odds of termination compared with communities with lower contraceptive prevalence $(\mathrm{aOR}=4.2 ; 95 \%$ CI $2.7-6.6)$.

The odds of pregnancy termination were 2.34 higher among women aged 20-24 than women aged 15-19. Other strong predictors were marital status, sexual debut before age 15 years and contraceptive prevalence. The odds of pregnancy termination were triple for women who were currently married or living together, and 
Table 2 Pregnancy termination among young women aged 15-24 in Nigeria, 2003-2018 NDHS

\begin{tabular}{|c|c|c|c|c|c|c|}
\hline \multirow[t]{2}{*}{ Variables } & \multirow{2}{*}{$\begin{array}{l}2003 \\
\text { Weighted \% }\end{array}$} & \multirow{2}{*}{$\begin{array}{l}2008 \\
\text { Weighted \% }\end{array}$} & \multirow{2}{*}{$\begin{array}{l}2013 \\
\text { Weighted \% }\end{array}$} & \multirow{2}{*}{$\begin{array}{l}2018 \\
\text { Weighted \% }\end{array}$} & \multicolumn{2}{|l|}{ Total } \\
\hline & & & & & Weighted\% & Unweighted cases \\
\hline Age group & $* *$ & ** & $* *$ & $* *$ & & $* *$ \\
\hline $15-19$ & 3.4 & 2.3 & 2.0 & 2.2 & 2.2 & 24,627 \\
\hline $20-24$ & 8.6 & 8.5 & 6.6 & 8.3 & 7.8 & 21,105 \\
\hline Education & * & $* *$ & $* *$ & $* *$ & & $* *$ \\
\hline No Education & 7.7 & 5.9 & 5.4 & 7.8 & 6.5 & 12,979 \\
\hline Primary & 6.5 & 7.0 & 6.7 & 7.2 & 6.9 & 6080 \\
\hline Secondary and above & 4.3 & 4.5 & 3.1 & 3.2 & 3.5 & 26,673 \\
\hline Marital status & $* *$ & $* *$ & $* *$ & $* *$ & & $* *$ \\
\hline Never married & 2.3 & 2.6 & 1.3 & 0.9 & 1.5 & 25,626 \\
\hline Currently married & 9.9 & 8.2 & 7.5 & 10.2 & 8.7 & 18,546 \\
\hline Living with a partner & 11.9 & 15.5 & 11.1 & 12.9 & 12.5 & 853 \\
\hline Previously married & 4.3 & 6.1 & 7.3 & 9.5 & 7.6 & 706 \\
\hline Wealth index & ns & ns & * & $* *$ & & $* *$ \\
\hline Poorest & 8.0 & 5.5 & 4.6 & 6.5 & 5.8 & 8165 \\
\hline Poorer & 5.9 & 5.7 & 5.1 & 6.1 & 5.7 & 9186 \\
\hline Middle & 5.1 & 4.8 & 4.2 & 6.0 & 5.1 & 9878 \\
\hline Richer & 5.7 & 5.9 & 4.0 & 3.7 & 4.5 & 9998 \\
\hline Richest & 4.8 & 4.4 & 3.4 & 2.4 & 3.4 & 8505 \\
\hline Ever use of any method of contraceptive & ** & ** & $* *$ & ** & * & $* *$ \\
\hline Never used & 4.3 & 4.0 & 1.4 & 4.7 & 4.3 & 27,254 \\
\hline Used & 12.0 & 12.4 & 4.6 & 7.1 & 9.9 & 3880 \\
\hline Age at first sex & $* *$ & ** & ** & ** & & $* *$ \\
\hline Never had sex & 0.0 & 0.0 & 0.0 & 0.0 & 0.0 & 17,359 \\
\hline Less than 15 & 9.7 & 8.6 & 7.4 & 11.1 & 8.9 & 6791 \\
\hline $15-17$ & 9.2 & 8.7 & 6.7 & 8.5 & 8.0 & 13,355 \\
\hline $18+$ & 6.2 & 6.8 & 5.6 & 6.5 & 6.2 & 8148 \\
\hline Forced sex & - & ns & * & ns & & ** \\
\hline No & 0.0 & 5.7 & 4.8 & 6.0 & 5.3 & 19,766 \\
\hline Yes & 0.0 & 12.0 & 9.5 & 11.3 & 10.7 & 1248 \\
\hline Frequency of reading newspaper & ns & ns & $* *$ & $* *$ & & ** \\
\hline Not at all & 6.2 & 5.2 & 4.8 & 5.3 & 5.2 & 35,696 \\
\hline Less than once a week & 4.0 & 6.6 & 2.5 & 3.1 & 3.7 & 5663 \\
\hline At least once a week or more & 5.5 & 4.2 & 2.5 & 2.8 & 3.5 & 4160 \\
\hline $\begin{array}{l}\text { Frequency of }{ }^{* *} \\
\text { listening to radio }\end{array}$ & ns & * & * & ns & & * \\
\hline Not at all & 6.1 & 5.4 & 4.2 & 5.0 & 4.9 & 17,607 \\
\hline Less than once a week & 5.8 & 6.7 & 5.0 & 5.0 & 5.3 & 10,209 \\
\hline At least once a week or more & 5.7 & 4.8 & 3.6 & 4.6 & 4.5 & 17,819 \\
\hline $\begin{array}{l}\text { Frequency of }{ }^{* * *} \\
\text { watching TV }\end{array}$ & ns & ns & $* *$ & ** & & ** \\
\hline Not at all & 6.1 & 5.5 & 4.7 & 6.3 & 5.6 & 21,279 \\
\hline Less than once a week & 3.2 & 5.9 & 4.3 & 3.9 & 4.4 & 7864 \\
\hline At least once a week or more & 6.1 & 4.9 & 3.7 & 3.5 & 4.1 & 16,483 \\
\hline No of living *** & $* *$ & ** & $* *$ & ** & & $* *$ \\
\hline
\end{tabular}


Table 2 Pregnancy termination among young women aged 15-24 in Nigeria, 2003-2018 NDHS (Continued)

\begin{tabular}{|c|c|c|c|c|c|c|}
\hline \multirow[t]{2}{*}{ Variables } & \multirow{2}{*}{$\begin{array}{l}2003 \\
\text { Weighted \% }\end{array}$} & \multirow{2}{*}{$\begin{array}{l}2008 \\
\text { Weighted \% }\end{array}$} & \multirow{2}{*}{$\begin{array}{l}2013 \\
\text { Weighted \% }\end{array}$} & \multirow{2}{*}{$\begin{array}{l}2018 \\
\text { Weighted \% }\end{array}$} & \multicolumn{2}{|l|}{ Total } \\
\hline & & & & & Weighted\% & Unweighted cases \\
\hline \multicolumn{7}{|l|}{ Children } \\
\hline 0 & 3.9 & 3.6 & 2.7 & 2.4 & 2.9 & 29,625 \\
\hline 1 & 8.8 & 8.3 & 7.5 & 9.8 & 8.6 & 8693 \\
\hline 2 & 8.5 & 8.8 & 5.7 & 10.4 & 8.3 & 4863 \\
\hline $3+$ & 12.1 & 7.5 & 6.7 & 7.6 & 7.6 & 2551 \\
\hline Ethnicity & * & $* *$ & $* *$ & $* *$ & & $* *$ \\
\hline Hausa & 6.6 & 6.3 & 5.7 & 7.0 & 6.4 & 11,058 \\
\hline Igbo & 4.0 & 3.1 & 2.4 & 1.7 & 2.5 & 6499 \\
\hline Yoruba & 2.0 & 1.8 & 2.8 & 2.4 & 2.4 & 5895 \\
\hline Others & 6.7 & 6.4 & 4.4 & 5.1 & 5.4 & 22,272 \\
\hline Religion & * & ns & $* *$ & $* *$ & & $* *$ \\
\hline Catholic & 5.5 & 4.5 & 2.6 & 3.2 & 3.6 & 5179 \\
\hline Other Christians & 4.9 & 5.9 & 3.8 & 3.3 & 4.3 & 18,222 \\
\hline Islam & 6.6 & 5.1 & 4.8 & 6.1 & 5.5 & 22,207 \\
\hline Place of Residence & ns & * & $* *$ & $* *$ & & $* *$ \\
\hline Urban & 5.7 & 4.6 & 3.4 & 3.5 & 3.8 & 17,109 \\
\hline Rural & 5.8 & 5.6 & 4.8 & 6.0 & 5.5 & 28,623 \\
\hline Region & $* *$ & $* *$ & $* *$ & $* *$ & & $* *$ \\
\hline North Central & 4.5 & 3.6 & 1.8 & 4.5 & 3.7 & 8356 \\
\hline North East & 9.2 & 6.0 & 4.8 & 6.0 & 5.9 & 8503 \\
\hline North West & 6.4 & 5.6 & 5.7 & 6.7 & 6.1 & 10,910 \\
\hline South East & 2.1 & 2.8 & 2.5 & 1.3 & 2.2 & 5401 \\
\hline South South & 7.2 & 12.4 & 4.7 & 4.6 & 6.8 & 6515 \\
\hline South West & 2.7 & 2.2 & 2.9 & 2.7 & 2.7 & 6047 \\
\hline Total & & & & & & 45,732 \\
\hline
\end{tabular}

${ }^{*}$ significant at $5 \%$ level $(p<0.05) ;{ }^{* *}=p<0.001 ; \mathrm{ns}=$ Non-significant

almost double for women who were previously married but not living together compared with young women who have never married. Young women who had initiated sexual activity before age 15 had 2.3 times higher odds of pregnancy termination than those who initiated sexual activity at a later age of 18 years or older. Young women living in communities (i.e. clusters) with higher contraceptive prevalence among young women (a proxy for higher access of reproductive health services by young women) had significantly higher odds of pregnancy termination than those in communities with lower contraceptive prevalence.

The odds of pregnancy termination were 1.4 times higher for women with primary education compared with young women with no education, but there was no evidence of a significant difference between women with secondary education and women with no education. Women from Igbo and Yoruba ethnic groups had significantly lower odds of pregnancy termination than women of Hausa ethnicity. There was evidence of a decline in the odds of pregnancy termination as the number of living children increased. There was some evidence that more frequent exposure to TV was associated with higher odds of pregnancy termination.

\section{Variations in pregnancy termination among young women across communities and states in Nigeria}

There were significant variations in pregnancy termination across communities (i.e clusters) and states in Nigeria. The cluster-level random variances from the variance components model (before controlling for the effect of any individual or contextual predictors of pregnancy termination) suggest that about $17 \%$ (i.e $(0.417+$ $0.263) /(0.417+0.263+3.29))$ of the total variation in pregnancy termination among the young women in Nigeria is attributable to community (i.e. cluster) level factors, while about $7 \%$ (i.e $(0.263) /(0.417+0.263+3.29)$ is attributable to state level factors, with the remaining $76 \%$ attributable to individual-level factors. 
Table 3 Multilevel parameter estimates and average odds ratios for pregnancy termination

\begin{tabular}{|c|c|c|c|c|c|c|}
\hline $\begin{array}{l}\text { PARAMETER } \\
\text { Const }\end{array}$ & $\begin{array}{l}\text { ESTIMATE } \\
-4.57\end{array}$ & S.E & AOR & \multicolumn{2}{|c|}{$95 \% \mathrm{Cl}$ of $\mathrm{AOR}$} & \\
\hline \multicolumn{7}{|l|}{ Year (2003) } \\
\hline 2008 & -0.13 & 0.105 & 0.88 & {$[0.71$} & 1.08] & \\
\hline 2013 & -0.41 & 0.188 & 0.66 & {$[0.46$} & $0.96]$ & * \\
\hline 2018 & 0.16 & 0.103 & 1.17 & {$[0.96$} & 1.44] & \\
\hline \multicolumn{7}{|l|}{ Age group (15-19) } \\
\hline $20-24$ & 0.85 & 0.076 & 2.34 & {$[2.02$,} & 2.72] & * \\
\hline \multicolumn{7}{|l|}{ Education (none) } \\
\hline Primary & 0.35 & 0.089 & 1.42 & {$[1.19$,} & 1.69] & * \\
\hline Secondary & 0.12 & 0.094 & 1.13 & {$[0.94$} & $1.36]$ & \\
\hline \multicolumn{7}{|c|}{ Marital status (never married) } \\
\hline Currently married & 1.10 & 0.102 & 3.00 & {$[2.46$,} & 3.67] & * \\
\hline Living with a partner & 1.14 & 0.162 & 3.13 & {$[2.28$} & 4.30] & * \\
\hline Previously married & 0.64 & 0.206 & 1.90 & {$[1.27$,} & $2.84]$ & * \\
\hline \multicolumn{7}{|l|}{ Watch TV (Never) } \\
\hline less than once a week & 0.11 & 0.095 & 1.12 & {$[0.93$,} & 1.34] & \\
\hline at least once a week & 0.31 & 0.081 & 1.36 & {$[1.16$,} & $1.60]$ & * \\
\hline \multicolumn{7}{|l|}{ Ethnicity (Hausa) } \\
\hline Igbo & -0.40 & 0.165 & 0.67 & {$[0.49$,} & $0.93]$ & * \\
\hline Yoruba & -0.66 & 0.172 & 0.52 & {$[0.37$} & $0.72]$ & * \\
\hline Others & -0.08 & 0.089 & 0.92 & {$[0.78$} & 1.10] & \\
\hline \multicolumn{7}{|l|}{ Number of children (none) } \\
\hline One & -0.25 & 0.077 & 0.78 & {$[0.67$,} & $0.91]$ & * \\
\hline Two & -0.50 & 0.094 & 0.61 & {$[0.50$} & $0.73]$ & * \\
\hline 3 and more & -0.84 & 0.121 & 0.43 & {$[0.34$} & $0.55]$ & * \\
\hline \multicolumn{7}{|l|}{ Age at first sex (18+) } \\
\hline Never had sex & -5.55 & 1.060 & 0.00 & {$[0.00$} & $0.03]$ & * \\
\hline Less than 15 & 0.84 & 0.094 & 2.32 & {$[1.93$,} & $2.78]$ & * \\
\hline $15-17$ & 0.50 & 0.790 & 1.65 & {$[0.35$} & $7.76]$ & \\
\hline \multicolumn{7}{|l|}{ Contextual factors } \\
\hline contracep prev_cluster & 1.43 & 0.231 & 4.18 & {$[2.66$,} & $6.57]$ & * \\
\hline \multicolumn{7}{|l|}{ Random effects } \\
\hline Level 3 - State & $0.10^{*}$ & 0.033 & $(I C C=0.03)$ & & & \\
\hline Level 2 - Cluster & $0.22^{*}$ & 0.056 & $(I C C=0.09)$ & & & \\
\hline
\end{tabular}

* - significant at $5 \%$ level $(p<0.05)$

After controlling for significant observable individual and contextual factors, about $9 \%$ (i.e. $(0.22+0.10) /(0.22+$ $0.10+3.29)$ and $3 \%$ (i.e $(0.10) /(0.22+0.10+3.29))$ of the total unexplained variation is attributable to unobserved cluster and state-level factors, respectively, with the remaining $88 \%$ attributable to unobserved individual characteristics. The state variations in pregnancy termination are highlighted in Fig. 2 showing 95\% simultaneous confidence intervals of state residuals [37]. Non-overlap of confidence intervals suggests a significant difference in odds of pregnancy termination between the states. The states are ordered from lowest to highest risk of pregnancy termination before any of the predictors are controlled for (Model 1). Before controlling for any predictors, states with lowest risk of pregnancy termination are predominantly in the South West, South East and North Central regions, while those with highest risk are predominantly in North West, North East and South South. Although, noticeably reduced, significant state-level variations remain when significant predictors are controlled for (Model 2). 


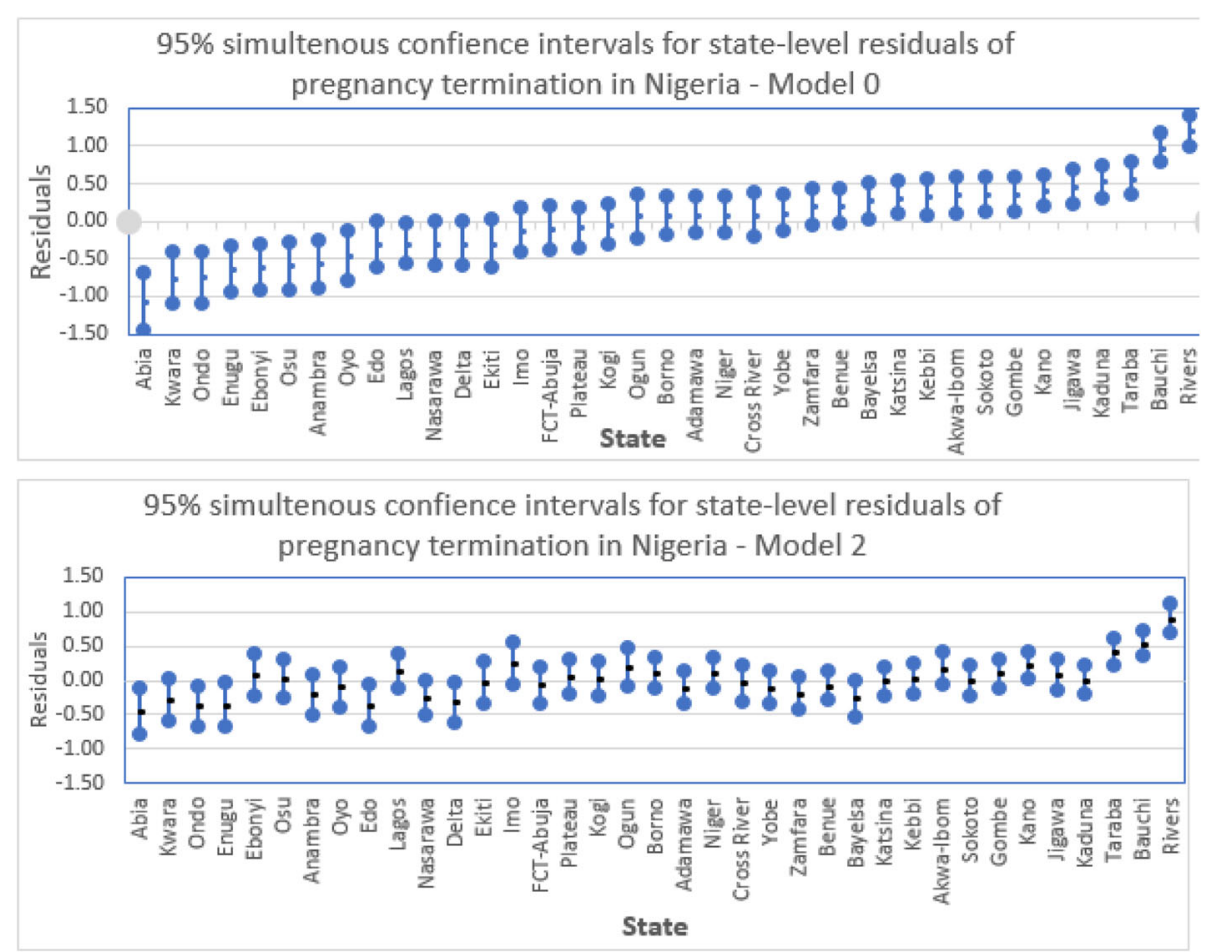

Fig. 2 State variations in pregnancy termination on pooled data for 2003-2018

\section{Discussion}

To our knowledge, this is the first comprehensive analysis of the NDHS from 2003 through 2018 that focuses specifically on the influence of both individual and contextual-level factors on pregnancy termination among women aged 15 to 24 years, a demographic group that is often overlooked in terms of research and public health interventions. Our key findings reveal a declining trend in pregnancy termination between 2003 and 2013, with a reversal in trend in 2018. Additionally, whilst the overall trend in pregnancy termination between 2003 and 2018 showed a decline, amongst some groups of young women there were disparities in the trends particularly for measures of socioeconomic status: young women with no education/primary education, and those from the poorest/poorer households showed no decline in pregnancy termination as opposed to those who were educated or were from wealthier households. The observed trend in pregnancy termination mirrored the trends in contraceptive use, and age at sexual debut, which were found to be significant factors associated with pregnancy termination in the multivariable model. The declining trend in pregnancy termination persisted especially from 2003 to 2013 after individual and contextual factors were controlled for. One potential explanation for these observed declining trends in termination could be due to the impact of the nationwide introduction of the school-based Family Life and HIV Education
(FLHE) curriculum in 2003, which was designed amongst other things to provide young people with sexual health literacy skills. Recent evidence shows that in states where the FLHE was effectively implemented, an improvement in sexual health knowledge of youth was found [38]. However, overall, implementation of this programme has dwindled in recent years due to limited continued financial and technical support from government agencies [38]. Moreover, in some regions the FLHE has been fraught with setbacks as individual states can modify the content of the curriculum coupled with the minimal acceptance of sexuality education particularly in regions with highly conservative religious and cultural values $[39,40]$. The sub-optimal implementation may be a factor contributing to the increase in early sexual initiation and pregnancy termination we observed in the data from 2013 to 2018 [32]. The declining trend between 2003 and 2013 we found, albeit with lower percentages, is similar to another study using DHS data for Nigeria but limited to married women of a wider age range (15-49 years) [13].

Surprisingly, we found a significant decline in contraceptive use from 2003 to 2018 for 15-24 year-old women. This important finding has not been evident in previous studies that aggregated data for a wider age range of women (15-49 years) in Nigeria [32], perhaps due to an ecological fallacy $[13,14,16,17]$. This calls into question whether the current National Reproductive 
Health Policy and Strategy to achieve Quality Reproductive Health and Sexual Health for All Nigerians including the provision of free family planning services in public facilities [41] has benefited all women of reproductive age in Nigeria. Our findings indicate that 15-24 year-old women are still being left behind on reproductive health matters despite increasing global attention to prioritising their health.

Another interesting finding was the influence of contextual level factors on pregnancy termination. Although the majority of the variation was at the individual level, significant variation in pregnancy termination was found between women aged 15-24 years across communities and states. While some community and state-level variables were not significantly associated with pregnancy termination, contraceptive prevalence at community level, which we derived from the individual-level variable 'contraceptive use' and then used as a proxy for reproductive health service accessibility within a community, was strongly positively associated with pregnancy termination. This suggests that communities with higher levels of reproductive health services, indicated by higher prevalence of contraceptive use, are linked to higher prevalence of pregnancy termination. This may indicate that despite availability of reproductive health services and contraceptives, factors such as pressure to have children and stigma surrounding non-marital sexual activity may hinder accessing them [42]. Interventions to discourage early marriage and dispel misconceptions and stigmatising attitudes towards contraceptive use such as scientifically accurate Comprehensive Sexuality Education (CSE) could help overcome these barriers and should be encouraged [18, 42]. However, these results contradict the findings of a previous study in Nigeria which found that residing in a community with contraceptive use at levels above the median for the community was associated with a lower likelihood of terminating pregnancy [20]. The disparity in the findings could again be attributable to the fact that the previous study [20] focused on a wider age range of women (1549 years). The integration of a wider age range of women in the study may have influenced the results as evidence has shown that older women have more contraceptive utilisation rate compared to younger women $[12,43]$.

Furthermore, at the individual level, we found that pregnancy termination was higher among women aged 20-24 than those aged 15-19 after controlling for confounding factors. This is not surprising as the NDHS report in 2018 revealed that the median age at first sexual intercourse is 17.2 years for women of reproductive age in Nigeria [32]; meaning that older women are more likely to be sexually active or exposed than their younger counterparts, which predisposes them to unwanted pregnancy, leading to abortions in many cases $[44,45]$. The higher risk of pregnancy termination among older women persisted, even after the age of sexual debut was controlled for. It is possible that younger women are less likely to report or seek abortion services due to cultural, socioeconomic and institutional barriers [42, 44]. Several other studies have reported similar findings [13, 15, 33].

Marital status was found to be a strong predictor of pregnancy termination. Currently married women aged 15-24 years, those living with a partner or previously married and not living with a partner were more likely to terminate pregnancy than never-married women. This could be linked to social desirability bias as never-married 1524 year old women may be reluctant to report pregnancy termination due to social stigma surrounding non-marital sexual activity or use of contraceptive [46]. However, this is inconsistent with the findings of previous school-based studies in Nigeria [16, 18] and facility-based studies among older women in Ethiopia [23], Burkina Faso [47] and Ghana [22], which found that unmarried youth are more likely to terminate a pregnancy than their married counterparts. The conflicting findings could be due to the difference how pregnancy termination was defined. In this study it was defined as any pregnancy that resulted in a miscarriage, abortion or stillbirth, which may not accurately reflect the main outcome of interest (induced abortion) [48]. While the school-based and facility-based studies measured only abortion. Although evidence from the DHS methodological report shows that only $2-5 \%$ of women who reported their pregnancy ending in miscarriage during a face-to-face interview changed their responses to induced abortion in a self-administered questionnaire [49].

Also, the results of this study revealed that 15-24 year-old women from both Igbo and Yoruba ethnic groups (predominantly in the South) have a lower tendency for pregnancy termination than those from Hausa ethnic group (predominantly in the North). The states with the highest risk of pregnancy termination are predominantly in the North rather than the South. This could conceivably be attributable to the disparity in the level of education, rates of early marriage, and cultural norms/beliefs across different ethnic groups in Nigeria [50]. For example, the average age at marriage for most girls in Northern Nigeria is 15 years compared with a median age of 24 years in the Southern regions of the country, Girls in the Southern regions are more likely to access formal education, while in the Northern regions, girls are less likely to access formal education and, consequently, experience sexual initiation at earlier ages [51-53]. It is also worth stressing that maternal mortality and under-five mortality rates in Nigeria vary considerably with some Northern states reporting nearly 50\% more deaths for both indicators than the national average $[31,54]$. Furthermore, the North-South disparity in 
education supports our findings that young women educated to primary level and above are less likely to terminate a pregnancy than their uneducated counterparts. Young women who are educated are more likely to have access to information and available services and possibly, delay childbearing and marry later than those with no education. These findings are consistent with the findings of other studies $[8,15,22,24]$. Also, in Ethiopia, evidence has shown that women with higher education were less likely to have induced abortion [55]. Lack of education and early sexual initiation/exposure, without doubt, expose young women to unintended pregnancy; leading to pregnancy termination [16].

\section{Strengths and limitations}

This study has key strengths due to utilising nationally representative datasets (from 2003 to 2018), a large sample size and the analysis adjusted for both individual and contextual (community and state) level factors. The analysis of variance indicated that around $24 \%$ of the variation in pregnancy termination among young women was due to the contextual level factors; supporting the value of including these in multivariable analyses. However, it, is not void of limitations that could have potential implications for the findings. One of the shortcomings is due to the cross-sectional study design which does not enable us to infer causal relationships between predictors and the outcome variable $[13,56]$. Another is that the NDHS depends on self-reported data collection, which can be subject to bias especially in a setting like Nigeria where abortion is legally restrictive; making pregnancy termination more likely to be under-reported. This could be averted by the use of indirect questioning techniques in elucidating responses to the question on pregnancy termination [20]. Furthermore, a terminated pregnancy could mean any type of pregnancy outcome other than one resulting in a live birth including: stillbirths, miscarriages and abortions, which could lead to overestimation of terminated pregnancy. Finally, this study did not control for facility-level factors which previous studies have suggested influence pregnancy termination $[25,57]$. However, our analysis indicated that residual confounding due to unobserved contextual level factors is only $12 \%$, therefore, the impact of this may be small.

\section{Conclusions}

This study provides insight into the trends and individual/contextual level predictors of pregnancy termination among women aged 15-24 years in Nigeria. Although most predictors of pregnancy termination occurred at the individual level, community and state level factors also predisposed women aged 15-24 years to terminate pregnancy. While there was a general decline in pregnancy termination among women aged 15-24 years in Nigeria, those with lower socioeconomic status may not have benefited from the current policy and programmes to the same extent as women of higher status. Consideration of whether a shift in policy direction and service provision is required, and these findings also highlights the need for further research to understand why the available services are not benefitting all women of reproductive age. The study suggests the need to shift from the current one size fits all service provision to targeted and tailored services to meet the SRH health needs of young women. Integrating an innovative communitybased health programme such as the Health Extension Program (HEP) into the existing services to expand access to SRH services may be a viable option. The findings show the need for multifaceted programs to address the influence of socio-cultural norms and contextual factors that influence pregnancy termination among young women in Nigeria. Policy interventions such as scientifically accurate Comprehensive Sexuality Education to delay early sexual debut and build agency to use contraception among young women especially those with no education, from the Hausa ethnic group and who reside in rural communities should be encouraged. This could reduce poor maternal health outcomes especially in Northern Nigeria with highly conservative religious and cultural values. Together these could make a positive impact on the SDG target to reduce maternal mortality.

\section{Supplementary information}

Supplementary information accompanies this paper at https://doi.org/10. 1186/s12884-020-03164-8.

Additional file 1. Background sample distribution of young people aged 15-24 by selected socio-demographic factors Nigeria, 2003 to 2018 NDHS.

\section{Abbreviations}

aOR: Adjusted Odds Ratio; CSE: Comprehensive Sexuality Education; EAs: Enumerated areas; FLHE: Family Life and HIV Education; FCT: Federal Capital Territory; HEP: Health Extension Program; ICC: Intraclass Correlation Coefficient; Cl: Confidence interval; NHREC: National Health Research Ethics Committee of Nigeria; NPC: National Population Commission; NDHS: Nigerian Demographic and Health Surveys; PQL: Predictive (or penalized) QuasiLikelihood.; QR-GCRF: Global Challenges Research Fund; RH: Reproductive Health; SRH: Sexual and Reproductive Health; SSA: Sub-Saharan Africa; STI: Sexually Transmitted Infection; SDG: Sustainable Development Goals; USAID: United States Agency for International Development; WHO: World Health Organization

\section{Acknowledgements}

Not applicable.

\section{Authors' contributions}

$\mathrm{LS}$ and $\mathrm{MM}$ conceived the project and obtained funding with input from AS and FO. MM and FO analyzed the data, all authors interpreted the findings. FO was a major contributor in writing the manuscript, with input from LS, MM and AS. All authors read and approved the final manuscript. 


\section{Authors' information}

This paper represents one phase of a programme of research that the authors are carrying out involving adolescent reproductive health in Northern Nigeria.

\section{Funding}

The work was funded by QR-GCRF pump-prime funding from the University of Hull, UK. The funding body had no role in the design of the study or collection, analysis, and interpretation of data or in writing the manuscript.

\section{Availability of data and materials}

The datasets analysed during the current study are available from the corresponding author on reasonable request.

\section{Ethics approval and consent to participate}

The study is based on secondary analysis of already anonymised Nigeria Demographic and Health Surveys (NDHS) data available in the public domain, so ethics approval was not required. Survey respondents voluntarily provided responses to the question "Ever terminated a pregnancy". During data collection the survey protocol was reviewed and approved by the National Health Research Ethics Committee of Nigeria (NHREC) and the ICF Institutional Review Board (NPC and ICF, 2019).

Relevant consents were obtained on behalf of the participants under 16 years before the data collection process. Although for non-therapeutic research (Research that does not involve physical contact through examination, treatment, or collection of bodily samples) in Nigeria, persons aged 13 years and above and emancipated minors can consent for themselves without parental consent in research.

\section{Consent for publication}

Not applicable.

\section{Competing interests}

The authors declare that they have no competing interests.

\section{Author details}

'Institute for Clinical and Applied Health Research, Faculty of Health Sciences University of Hull, Hull, UK. ${ }^{2}$ Department of Criminology and Sociology, Faculty of Arts, Cultures and Education, University of Hull, Hull, UK. ${ }^{3}$ School of Nursing and Midwifery, Aga Khan University (East Africa campus), Kampala, Uganda.

Received: 18 May 2020 Accepted: 11 August 2020

Published online: 22 September 2020

\section{References}

1. Guttmacher Institute. Abortion in Africa. 2018; Available from https://www. guttmacher.org/sites/default/files/factsheet/ib_aww-africa.pdf. Accessed 8th May 2020.

2. Ganatra B, Gerdts C, Rossier C, Johnson BR, Tuncalp O, Assifi A, Sedgh G, Singh S, Bankole A, Popinchalk A, Bearak J, Kang Z, Alkema L. Global, regional, and subregional classification of abortions by safety: estimates from a Bayesian hierarchical model. Lancet. 2017;390(10110):2372-81. https://doi.org/10.1016/S0140-6736(17)31794-4

3. Munakampe MN, Zulu JM, Michelo C. Contraception and abortion knowledge, attitudes and practices among adolescents from low and middle-income countries: a systematic review. BMC Health Serv Res. 2018; 18(1):909. https://doi.org/10.1186/s12913-018-3722-5.

4. Kabiru CW, Ushie BA, Mutua MM, Izugbara CO. Previous induced abortion among young women seeking abortion-related care in Kenya: a crosssectional analysis. BMC Pregnancy Childbirth. 2016;16:104. https://doi.org/10. 1186/s12884-016-0894-z.

5. Kulczycki A. The imperative to expand provision, access and use of misoprostol for post-abortion care in sub-Saharan Africa. 2010-14. Afr J Reprod Health. 2016;20(3):25

6. Abiodun OM, Balogun OR. Sexual activity and contraceptive use among young female students of tertiary educational institutions in Ilorin, Nigeria. Inte Reprod Health J Contracept. 2009;79(2):146-9. https://doi.org/10.1016/j. contraception.2008.08.002.

7. Oriji VK, Jeremiah I, Kasso T. Induced abortion amongst undergraduate students of the University of Port Harcourt. Niger J Med. 2009;18:199-202.
8. Oyefabi AO, Nmadu AG, Yusuf MS. Prevalence, perceptions, consequences, and determinants of induced abortion among students of the Kaduna State University, Northwestern Nigeria. J Med Trop. 2016;18:86-92.

9. Atuhaire $\mathrm{S}$. Abortion among adolescents in Africa: a review of practices, consequences, and control strategies. Internal journal of health planning and management. Int J Health Plann Mgmt. 2019;34:e1378-86.

10. Ordinioha B, Owhonda G. Clandestine abortion in Port Harcourt: users' profile and motivation. Niger J Med. 2008;17:33-6.

11. World Health Organisation. Recommendations on adolescent sexual and reproductive health and rights. Geneva: World Health Organization; Licence: CC BY-NC-SA 3.0 IGO; 2018. Available at: https://apps.who.int/iris/bitstream/ handle/10665/275374/9789241514606-eng.pdf. Accessed 8 $8^{\text {th }}$ May 2020.

12. Bankole A, Adewole IF, Hussain R, Awolude O, Singh S, Akinyemi JO. The incidence of abortion in Nigeria. Int Perspect Sex Reprod Health. 2015;41(4): 170-81. https://doi.org/10.1363/4117015.

13. Yaya S, Amouzou A, Uthman OA, Ekholuenetale M, Bishwajit G, Udenigwe $O$, Shah V. Prevalence and determinants of terminated and unintended pregnancies among married women: analysis of pooled cross-sectional surveys in Nigeria. BMJ Global Health. 2018;3(2):e000707. https://doi.org/10. 1136/bmjgh-2018-000707.

14. Aderibigbe, SA; Araoya, MO; Akande, TM; Monehim, JO; Musa, Ol \& Babatunde, OA Teenage Pregnancy and Prevalence of Abortion among Inschool Adolescents in North Central, Nigeria. Canadian centre of science and education. 2011. Available from: http://www.ccsenet.org/journal/index. php/ass/article/view/8877. Accessed 8th May 2020.

15. Ofori-amankwah. Determinants of unsafe abortion among adolescents and young adults in ghana kit (royal tropical institute) development, policy and practice Vrije Universiteit Amsterdam Amsterdam, the Netherlands. 2013; Available from https://pdfs.semanticscholar.org/a6fd/1006c1fd31784af1 77cdf669895e0c587f22.pdf. Accessed $8^{\text {th }}$ May 2020.

16. Cadmus EO, Owoaje ET. Knowledge about complications and practice of abortion among female undergraduates in the university of Ibadan, Nigeria. Ann Ibadan Postgraduate Med. 2011;9(1):19-23.

17. Ajewole I, Fasoro AA, Agbana RD. Factors influencing and dangers of criminal abortion among teenagers in a senior secondary school in Ekiti state, Nigeria. Eur J Pharm Med Res. 2018;5(8):121-5.

18. Murray NC, Winfrey WR, Chatterji M, Moreland SR, Dougherty L, Okonofua F. Factors related to induced abortion among young women in Edo State, Nigeria. Stud Fam Plann. 2006;37(4):251-68.

19. Hall M, Chappell LC, Parnell BL, Seed PT, Bewley S. Associations between Intimate Partner Violence and Termination of Pregnancy: A Systematic Review and Meta-Analysis. PLoS Med. 2014;11(1). https://doi.org/10.1371/ journal.pmed.1001581.

20. Antai, Adaji. Community-level influences on women's experience of intimate partner violence and terminated pregnancy in Nigeria: a multilevel analysis. BMC Pregnancy Childbirth. 2012;12:128. https://doi.org/10.1186/ 1471-2393-12-128.

21. Maranhao TA, GomesII KRO, Barros III IC. Predictive factors of abortion among teenagers with obstetric experience. Women's Health. 2016;19(3): 494-508.

22. Adjei G, Enuameh Y, Asante K, Baiden FA, Nettey O, Abubakari S, Mahama E, Gyaase S, Owusu-Agyei S. Predictors of abortions in Rural Ghana: a crosssectional study. BMC Public Health. 2015;15:202. https://doi.org/10.1186/ s12889-015-1572-1.

23. Denberu B, Alemseged F, Segni H. Determinants of abortion among youth seeking reproductive health Care in Selected Health Facilities, in Addis Ababa, Ethiopia. Glob J Reprod Med. 2017;1(2):555560.

24. Appiah-Agyekum N, Sorkpor, Ofori-Mensah S. Determinants of abortion decisions among Ghanaian university students. Int J Adolescent Med Health. 2014;27(1):79-84. https://doi.org/10.1515/ijamh-2014-0011.

25. Frederico M, Michielsen $K$, Arnaldo C, Decat P. Factors influencing abortion decision-making processes among young women. Int J Environ Res Public Health. 2018;15(2):329. https://doi.org/10.3390/ijerph15020329.

26. Oyewale I, Adeniji, MA. Regional Imbalances and Inequalities in Nigeria: Causes, Consequences and Remedies Research on Humanities and Social Sciences. www.iiste.org ISSN (Paper)2224-5766 ISSN (Online)2225-0484 (Online). 2014. Vol.4, No.18. Accessed 17 Aug 2019.

27. Vinh NT, Tuan PC. Factors influencing unintended pregnancy and abortion among unmarried youth in Vietnam: a literature review. Tap Chi Y Te Cong Cong. 2015;3(2):3-16. 
28. Elul B. Determinants of induced abortion: an analysis of individual, household and contextual factors in Rajasthan, India. J Biosocial Sci. 2011; 43(1):1-17.

29. World Health Organisation. Nigeria fights high maternal mortality through improved quality of care [Online] Available at https://www.afro.who.int/ news/nigeria-fights-high-maternal-mortality-through-improved-quality-care. Accessed $8^{\text {th }}$ May 2020.

30. World Health Organization. Trends in maternal mortality 2017. Available [Online] https://www.who.int/news-room/fact-sheets/detail/maternalmortality. Accessed $8^{\text {th }}$ May 2020.

31. World Bank. Poverty reduction in Nigeria in the last decade. 2016. Available [Online] http://documents.worldbank.org/curated/en/103491483646246005/ pdf/ACS19141-REVISED-PUBLIC-Pov-assessment-final.pdf. Accessed 8th May 2020.

32. National Population Commission (NPC) [Nigeria] and ICF. Nigeria Demographic and Health Survey. Abuja, Nigeria, and Rockville, Maryland, USA: NPC and ICF; 2018.

33. Ibisomi L, Odimegwu C. Pregnancy Termination in Sub-Saharan Africa: The Need for Refined Data. Int J Health Res. 2008;1(4):207-24 (e147p70-88).

34. Goldstein H. Multilevel statistical models (3rd edition). London: Arnold; 2003.

35. Siddiqui O, Hedeker D, Flay BR, Hu FB. Intraclass correlation estimates in a school-based smoking prevention study: outcome and mediating variables, by sex and ethnicity. Am J Epidemiol. 1996;144(4):425-33.

36. Hedeker D, Gibbsons RD. MIXOR: a computer programme for mixed-effects ordinal regression analysis. Comput Methods Programs Biometrics. 1996;49: 157-76.

37. Rasbash J, Steele F, Browne W, Goldstein H. A users guide to MLwiN, Version 2.26. Bristol: Centre for Multilevel Modeling, University of Bristol; 2012.

38. Udegbe BI, Fayehun F, Uche C, Isiugo-Abanihe UC, Nwagwu WA, Nwokocha E. Evaluation of the implementation of family life and HIV Education programme in Nigeria. Afr J Reprod Health. 2015;19(2):79-93.

39. Igbokwe UL, Ogbonna CS, Ezegbe BN, Nnadi EM, Eseadi C. Viewpoint on family life and HIV Education curriculum in Nigerian secondary schools. J Int Med Res. 2019;48(1):1-6.

40. Woods SY, Rogow D. Can sexuality education advance gender equality and strengthen education overall? Learning from Nigeria's Family Life and HIV education program. New York: International Women's Health Coalition; 2015. https://iwhc.org/wp-content/uploads/2015/12/Nigeria_FLHE_FINALnospreads.pdf. Accessed $8^{\text {th }}$ May 2020.

41. National Ministry of Health. National Reproductive Health Policy.2017. Available from https://www.health.gov.ng/doc/RH\%20Soft\%20Copy.pdf. Accessed $8^{\text {th }}$ May 2020.

42. Chandra-Mouli V, McCarraher DR, Phillips SJ, Williamson NE, Hainsworth G. Contraception for adolescents in low and middle-income countries: needs, barriers, and access. Reprod Health. 2014;11:1.

43. FP2020. Family Planning Summit Concept Note, July 11, 2017 - London UK. Available from: http://summit2017.familyplanning2020.org/. Accessed May $8^{\text {th }} 2020$.

44. Shah HI, Ahman E. Unsafe abortion differential in 2008 by age and developing country region: high burden among young women. Reprod Health Matters. 2012;20(39):169-73.

45. Ma Q, Ono-Kihara M, Cong L, Xu G, Pan X, Zamani S, Ravari SM, Zhang D, Homma T, Kihara M. Early initiation of sexual activity: a risk factor for sexually transmitted diseases, HIV infection, and unwanted pregnancy among university students in China. BMC Public health. 2009;9:111. https:// doi.org/10.1186/1471-2458-9-111.

46. Zimmerman LA, Bell SO, Li Q, Morzenti A, Anglewicz P. Individual, community and service environment factors associated with modern contraceptive use in five Sub-Saharan African countries: A multilevel, multinomial analysis using geographically linked data from PMA2020. PLoS ONE. 2019;14(6):e0218157. https://doi.org/10.1371/journal.pone.0218157.

47. Ilboudo PG, Somda SM, Sundby J. Key determinants of induced abortion in women seeking postabortion care in hospital facilities in Ouagadougou, Burkina Faso. Int J Women's Health. 2014;6:565-72. https://doi.org/10.2147/ IJWH.S60709.

48. Song M, Lin F, Sandra E, Ward SE, Fine JP. Composite Variables: When and how. Nurs Res. 2016:62(1):45-9. https://doi.org/10.1097/NNR. ob013e3182741948.
49. Fu H, Darroch JE, Henshaw SK, Kolb E. Measuring the extent of abortion underreporting in the 1995 National Survey of family growth. Fam Plan Perspect. 1998;30(3):128-38.

50. Ifijeh $\mathrm{G}$ and Osayande. Issues in girl-child education in Nigeria: implications for library and information support.2011; Gender \& Behaviour; Volume 9 Number 2. Center for Psychological Studies \& Services Ile-Ife, Nigeria.

51. Erulkar A.S and Bello, M. The Experience of Married Adolescent Girls in Northern Nigeria . The Population Council, Inc 2011. Available from https:// www.ohchr.org/Documents/Issues/Women/WRGS/ForcedMarriage/NGO/ PopulationCouncil24.pdf. Accessed May $8^{\text {th }} 2020$.

52. British Education. Girls Education in Nigeria, Issues, Influencers and Action; 2016. Available from https://www.britishcouncil.org/sites/default/files/britishcouncil-girls-education-nigeria-report.pdf. Accessed May $8^{\text {th }} 2020$.

53. Bjorkman M, Leight J, Sharma V. Community Health Educators and Maternal Health: Evidence from a Randomized Controlled Trial. Available from https:// editorialexpress.com/cgi-bin/conference/download.cgi?db_name=CSAE201 8\&paper_id=195. Accessed May $8^{\text {th }} 2020$.

54. Sharma V, Brown W, Kainuwa MA, Leight J. High maternal mortality in Jigawa State, Northern Nigeria estimated using the sisterhood method. BMC Pregnancy Childbirth. 2017;17(163). https://doi.org/10.1186/s12884-017-1341-5.

55. Tesfaye T, Hambisa MT, Semahegn A. Induced abortion and associated factors in health facilities of Guraghe zone, Southern Ethiopia. J Pregnancy. 2014;295732. https://doi.org/10.1155/2014/295732.

56. Setia MS. Methodology series module 3: cross-sectional studies. Indian J Dermatol. 2016;61(3):261-4. https://doi.org/10.4103/0019-5154.182410.

57. Mantshi ET, Laetitia CR. I am all alone: factors influencing the provision of termination of pregnancy services in two South African provinces. Glob Health Action. 2017;10:1-10. https://doi.org/10.1080/16549716.2017.1347369.

\section{Publisher's Note}

Springer Nature remains neutral with regard to jurisdictional claims in published maps and institutional affiliations.

Ready to submit your research? Choose BMC and benefit from:

- fast, convenient online submission

- thorough peer review by experienced researchers in your field

- rapid publication on acceptance

- support for research data, including large and complex data types

- gold Open Access which fosters wider collaboration and increased citations

- maximum visibility for your research: over $100 \mathrm{M}$ website views per year

At $\mathrm{BMC}$, research is always in progress.

Learn more biomedcentral.com/submissions 